\title{
NUMERICAL RESEARCH OF DEGENERATE DYNAMIC BALANCE MODEL OF THE CELL CYCLE
}

\author{
S. I. Ebel, South Ural State University, Chelyabinsk, Russian Federation, \\ ebelsi@susu.ac.ru.
}

\begin{abstract}
The mathematical model of the cell cycle is considered. It is shown that a balance dynamic model of the cell cycle for the mitotic cell division is degenerate. The method of constructing of the degenerate balance dynamic model of the cell cycle is submitted. The methods of the theory of degenerate groups and the numerical methods for the initial value problem for the Leontiev type systems are applied to the studied model. The numerical investigation of a model example of a degenerate balance dynamic model of the cell cycle is performed. The construction of the mathematical model will allow to reduce a time of studying of the processes occurring in the cell, to develop the possible scenarios of development in accordance with the changing of environmental factors and to optimize the process of removing of the division defect.
\end{abstract}

Keywords: model of the cell cycle, numerical solution, Leontieff type models, computational efficiency of the algorithm.

\section{Introduction}

The subject of research is at the intersection of three directions. The first one is the research of the Showalter - Sidorov problem for the Leontieff type systems as a special finite case of Sobolev type equation based on the theory of degenerate groups. The theory of this direction is developing by S.A. Zagrebina, A.A. Zamyshlyaeva, M.A. Sagadeeva, N.A. Manakova and others [1-5] under the leadership of G.A. Sviridyuk in Chelyabinsk mathematical school.

The second direction is the numerical research of models of Leontieff type having application in economics and engineering. The numerical research of the Cauchy problem for Leontieff type systems was performed by G.A. Sviridyuk, S.V. Brycheva and I.V. Burlachko [6, 7]. The Showalter - Sidorov problem for Leontieff type systems in the economics is considered by A.V. Keller, T.A. Shishkina [8]. The dynamic measurement problems in the technique are considered by A.L. Shestakov, A.V. Keller, E.I. Nazarova, Yu.V. Khudyakov [9-11].

The third direction is the research of the balance dynamic model of the cell cycle, which was conceptually proposed by N.D. Gernet and A.I. Bozhkov [12]. But its detailed research showed that this model for the mitotic cell division is degenerate. During mitosis, the genetic information is not synthesized and the hereditary material can not stock up. This corresponds to the economic models, where the individual elements (e.g., a labor) are not stocking. Note that V.V. Leontieff repeatedly accented that the balance models are naturally degenerate [13].

The paper presents the results of the research of balance dynamic model of the cell cycle. First of all we show that this model is degenerate. The technique of composing of the degenerate balance dynamic model of the cell cycle is developed on the base of the methods of the input-output balance. The model example is presented. A numerical algorithm for solution of the Showalter - Sidorov problem for the Leontieff type systems was adapted 
to research of the balance dynamic model of the cell cycle to perform computational experiments. Finally, the results of a computational experiment for a model example and an analysis of their adequacy are presented.

\section{Dynamic balance model of the cell cycle}

A living cell produces a new cell during the time interval $\left[t_{0}, t_{0}+\tau\right]$, where $t_{0}$ is a initial moment of the cell cycle, $\tau$ is a time of a new cell creation. The time $t \in\left[t_{0}, t_{0}+\tau\right]$ determines the current moment of the process of new cell creating. It is assumed that at the initial moment $t_{0}$ the cell has a real potential (matter reserve) $m_{0}=m\left(t_{0}\right)$, an energy potential (energy reserve) $e_{0}=e\left(t_{0}\right)$ and the information potential (information resource) $u_{0}=u\left(t_{0}\right)$.

A vector $B x_{0}=B x\left(t_{0}\right)=\left(m_{0}, e_{0}, u_{0}\right)$ determines the initial reserves of a matter, an energy and an information in the cell. The completion of a new cell creation is determined by the existence of a double reserve $B x\left(t_{0}+\tau\right)=2 B x\left(t_{0}\right)=2 B X_{0}$.

A vector $x(t)$ determines the volume of a matter production $\left(x_{1}(t)\right)$, an energy $\left(x_{2}(t)\right)$ and an information $\left(x_{3}(t)\right)$ at the moment $t \in\left[t_{0}, t_{0}+\tau\right]$. $A$ and $B$ are square matrices of order $n$. Matrix $A$ is a matrix of unit costs of a matter, an energy and an information which are necessary to maintain the functioning of the cell. Matrix $A$ shows cost norms of $i$-th resource on the synthesis of $j$-th resource unit. Matrix $B$ is a matrix of unit costs. It determines norms of increment of intracellular flow of $i$-th resource on a gain of $j$-th resource unit. Let us consider only linear production process [12]. Then the costs $a_{k j}\left(t_{0}\right) x(t)$ of $k$-th resource in the moment $t$ for the production of $j$-th resource having volume $x_{j}(t)$ linearly depends on $x_{j}(t)$. If $a_{r j}(t)=0$, then $r$-th resource is not consumed in the production of $j$-th resource. The coefficients $a_{r j}(t)$ form a matrix $A(t)=\left(a_{r j}(t)\right)$, $r, j=\overline{1,3}$ of direct costs of resources in the cell.

Each component of a vector $f(t)=\left(f_{m}(t), f_{e}(t), f_{u}(t)\right)$ consists of three terms $f_{i}(t)=f_{i 0}(t)+f_{i 1}(t)-f_{i 2}(t)$, where $f_{i 0}(t)$ is a meeting the needs of the cell by produced resources, $f_{i 1}(t)$ is a meeting the needs of the cell by external environment resources, $f_{i 2}(t)$ is a outflow of produced resources of the cell into the external environment at the moment $t$.

In view of the mentioned circumstances the following balance relation is executed at each moment:

$$
x(t)=A x(t)+B \frac{d x(t)}{d t}+f(t)
$$

with the conditions

$$
x(t) \geq 0, B \frac{d x(t)}{d t} \geq 0
$$

In this model we take into account the interacting intracellular flows (matter, energy, information).

In the beginning of its division a cell has initial reserves of matter, energy and information. In the preparatory phase (presynthetic, synthetic and postsynthetic) just before mitosis a DNA replication doubles, the cell is actively grows in size and stores the matter. During mitosis, genetic information is not synthesized and hereditary material can not stock up for future use. We consider a degenerate balance dynamic model of the cell cycle as a special case. 
As part of a degenerate dynamic balance model of the cell cycle (1) we consider the flows of a matter, an energy, an information for the construction of the matrices elements with the release of the three groups of the corresponding flows of a matter, an energy, an information. We will call them groups of structural elements.

Intracellular flow of matter (S). The reactions of respiration supply the cell with not only an energy, but also with a construction protein for the synthesis of a different molecules.

Intracellular flow of energy (E) consists of two groups. The first one is a group of anabolic reactions. They are reactions of fusion of large molecules from smaller and simpler ones, for this process an energy is expended. The second group is a group of catabolic reactions. They are reactions of decomposition of larger molecules into smaller and simpler ones, with energy release. A metabolism of the cell is the set of catabolic and anabolic reactions which occur in the cell at any given moment.

Intracellular flow of information (I). Due to the flow of an information the cell gets a structure corresponding to the criteria of the living, supports it in time, as well as transfers it among generations. A nucleus, macromolecule bringing an information (messenger RNA) into the cytoplasm, a cytoplasmic translation apparatus (transfer RNA, ribosomal polynomials), and others are involved in the flow of an information.

The mitosis provides a transmission of characteristics and properties among generations of cells during the development of a multicellular organism. Due to the distribution of chromosomes all cells of a single organism are genetically identical. The mitosis determines the most important phenomenons of life activity: growth, development and repair of tissues and organs, asexual reproduction of organisms.

We introduce the following notation:

$\ell$ - the number of subdivisions of matter flows which are needed to maintain of the functioning of the cell, as well as for the reserve of matter;

$m$ - the number of subdivisions of energy flows which are needed to maintain of the functioning of the cell, as well as for the reserve of matter;

$k$ - the number of subdivisions of information flows which are needed to maintain of the functioning of the cell, as well as for the reserve of matter;

$n$ - the common number of subdivisions of flows of a matter, an energy, an information which are needed to maintain of the functioning of the cell, as well as for the reserve of matter;

There are the following structural elements in group S:

- a splitting of lipids, nucleic acids, proteins, fats (lysosomes);

- a synthesis of proteins, fats, carbohydrates, and transportation (ESR, Golgi complex, ribosome).

Therefore, $\ell=2$.

There are the following structural elements in group E:

- a synthesis of large molecules from smaller with energy absorption (anabolism);

- a splitting of larger molecules into smaller with energy release (catabolism).

Therefore, $m=2$.

There are the following structural elements in group I:

- a regulation of all kinds of cellular activity (nucleus);

- a transfer of genetic information of DNA.

Therefore, $m=2$ и $n=6$. 
Let:

$X_{i j}$ be a matrix of direct costs, reflecting the volume of a matter, an energy and an information of $i$-th structural element by $j$-th structural element to maintain the functioning of the cell;

$Z_{i j}$ be a matrix of the reverse volumes of a matter, an energy and an information of $i$-th structural element by $j$-th structural element to maintain the functioning of the cell and for the preparation of a cell division;

$X_{i}$ be the common number of flows of a matter, an energy, an information which are used for the functioning of the cell during the reproduction process of a new one.

Table 1

The degenerate dynamic balance model of the cell cycle is presented as a table

\begin{tabular}{|c|c|c|c|c|c|c|c|c|c|}
\hline \multirow{2}{*}{\multicolumn{2}{|c|}{$\begin{array}{l}\text { Intracellular } \\
\text { flows }\end{array}$}} & \multicolumn{3}{|c|}{$\begin{array}{l}\text { Intracellular flow, } \\
\text { which is needed } \\
\text { to maintain the } \\
\text { functioning of the } \\
\text { cell }\end{array}$} & \multicolumn{3}{|c|}{$\begin{array}{l}\text { Increment of } \\
\text { intracellular flows }\end{array}$} & \multirow[t]{2}{*}{$\begin{array}{l}\text { Needs } \\
\text { of the } \\
\text { cell }\end{array}$} & \multirow[t]{2}{*}{$\begin{array}{l}\text { Total } \\
\text { flow }\end{array}$} \\
\hline & & $\mathrm{S}$ & $\mathrm{E}$ & I & $\mathrm{S}$ & $\mathrm{E}$ & I & & \\
\hline$i$ & J & $\begin{array}{l}1 \\
\cdots \\
\ell\end{array}$ & $\begin{array}{c}\ell+1 \\
\ldots \\
\ell+m\end{array}$ & $\begin{array}{c}\ell+m+1 \\
\cdots \\
n\end{array}$ & $\begin{array}{l}1 \\
\cdots \\
\ell\end{array}$ & $\begin{array}{c}\ell+1 \\
\ldots \\
\ell+m\end{array}$ & $\begin{array}{c}\ell+m+1 \\
\ldots \\
n\end{array}$ & & \\
\hline $\begin{array}{l}1 \\
\cdots \\
\ell\end{array}$ & $\mathrm{S}$ & $x_{i j}^{S S}$ & $x_{i j}^{S E}$ & $x_{i j}^{S I}$ & $z_{i j}^{S S}$ & $z_{i j}^{S E}$ & $z_{i j}^{S I}$ & $f_{i}^{S}$ & $X_{i}^{S}$ \\
\hline $\begin{array}{c}+1 \\
\ldots \\
\ell+m\end{array}$ & $\mathrm{E}$ & $x_{i j}^{E S}$ & $x_{i j}^{E E}$ & $x_{i j}^{E I}$ & $z_{i j}^{E S}$ & $z_{i j}^{E E}$ & $z_{i j}^{E I}$ & $f_{i}^{E}$ & $X_{i}^{E}$ \\
\hline $\begin{array}{c}\ell+m+1 \\
\ldots \\
n\end{array}$ & $\mathrm{I}$ & $x_{i j}^{I S}$ & $x_{i j}^{I E}$ & $x_{i j}^{I I}$ & $z_{i j}^{I S}$ & $z_{i j}^{I E}$ & $b_{i j}^{I I}$ & $f_{i}^{I}$ & $X_{i}^{I}$ \\
\hline
\end{tabular}

In our model of the cell cycle the specific flows of a matter, an energy, an information which are needed to maintain the functioning of the cell consist of nine blocks and form the matrices:

$X^{S S}=\left\|x_{i j}\right\|, i=j=\overline{1, \ell}$ is a consumption matrix of $i$-th matter flow by $j$-th flow of matter;

$X^{S E}=\left\|x_{i j}\right\|, i=\overline{1, \ell}, j=\overline{\ell+1, \ell+m}$ is a consumption matrix of $i$-th matter flow by $j$-th flow of an energy;

$X^{S I}=\left\|x_{i j}\right\|, i=\overline{1, \ell}, j=\overline{\ell+m+1, n}$ is a consumption matrix of $i$-th matter flow by $j$-th flow of an information;

$X^{E S}=\left\|x_{i j}\right\|, i=\overline{\ell+1, \ell+m}, j=\overline{1, \ell}$ is a consumption matrix of $i$-th energy flow by $j$-th flow of matter;

$X^{E E}=\left\|x_{i j}\right\|, i=j=\overline{\ell+1, \ell+m}$ is a consumption matrix of $i$-th energy flow by $j$-th flow of an energy;

$X^{E I}=\left\|x_{i j}\right\|, i=\overline{\ell+1, \ell+m}, j=\overline{\ell+m+1, n}$ is a consumption matrix of $i$-th energy flow by $j$-th flow of an information; 
$X^{I S}=\left\|x_{i j}\right\|, i=\overline{\ell+m+1, n} j=\overline{1, \ell}$ is a consumption matrix of $i$-th information flow by $j$-th flow of matter;

$X^{I E}=\left\|x_{i j}\right\|, i=\overline{\ell+m+1, n}, j=\overline{\ell+1, \ell+m}$ is a consumption matrix of $i$-th information flow by $j$-th flow of an energy;

$X^{I I}=\left\|x_{i j}\right\|, i=\overline{\ell+m+1, n}, j=\overline{\ell+m+1, n}$ is a consumption matrix of $i$-th information flow by $j$-th flow of an information.

The increment of intracellular flows of a matter, an energy and an information can also be divided into nine matrices:

$Z^{S S}=\left\|z_{i j}\right\|, i=j=\overline{1, \ell}$ is a matrix increment of $i$-th flow of matter due to consumption of $j$-th matter flow;

$Z^{S E}=\left\|z_{i j}\right\|, i=\overline{1, \ell} ; j=\overline{\ell+1, \ell+m}$ is a matrix increment of $i$-th flow of matter due to consumption of $j$-th energy flow;

$Z^{S I}=\left\|z_{i j}\right\|, i=\overline{1, \ell}, j=\overline{\ell+m+1, n}$ is a matrix increment of $i$-th flow of matter due to consumption of $j$-th information flow;

$Z^{E S}=\left\|z_{i j}\right\|, i=\overline{\ell+1, \ell+m}, j=\overline{1, \ell}$ is a matrix increment of $i$-th energy flow due to consumption of $j$-th matter flow;

$Z^{E E}=\left\|z_{i j}\right\|, i=j=\overline{\ell+1, \ell+m}$ is a matrix increment of $i$-th energy flow due to consumption of $j$-th energy flow;

$Z^{E I}=\left\|z_{i j}\right\|, i=\overline{\ell+1, \ell+m}, j=\overline{\ell+m+1, n}$ is a matrix increment of $i$-th energy flow due to consumption of $j$-th information flow;

$Z^{I S}=\left\|z_{i j}\right\|, i=\overline{\ell+m+1, n} j=\overline{1, \ell}$ is a matrix increment of $i$-th information flow due to consumption of $j$-th matter flow;

$Z^{I E}=\left\|z_{i j}\right\|, i=\overline{\ell+m+1, n}, j=\overline{\ell+1, \ell+m}$ is a matrix increment of $i$-th information flow due to consumption of $j$-th energy flow;

$Z^{I I}=\left\|z_{i j}\right\|, i=j=\overline{\ell+m+1, n}$ is a matrix increment of $i$-th information flow due to consumption of $j$-th information flow.

A vector $f_{i}$ can also be divided into blocks:

$f_{i}^{S}, i=\overline{1, \ell}$ is a sum, which includes the exchange of flows of matter with the external environment;

$f_{i}^{E}, i=\overline{\ell+1, \ell+m}$ is a sum, which includes the exchange of flows of an energy with the external environment;

$f_{i}^{I}, i=\overline{\ell+m+1, n}$ is a sum, which includes the exchange of flows of an information with the external environment.

Based on these tables we calculate the matrix of specific direct $\operatorname{costs} A=\left(a_{i j}\right)=\left(\frac{x_{i j}}{X_{i}}\right)$ - the specific amount of a matter, an energy and an information which are needed to maintain of the functioning of the cell and the matrix $B=\left(b_{i j}\right)=\left(\frac{z_{i j}}{X_{i}}\right)$ the specific amount of a matter, an energy and an information which are used for the increment of intracellular flows.

\section{An example of a dynamic balance model of the cell cycle}

Consider the model example of constructing of a balance dynamic model of the cell cycle. We present a degenerate dynamic balance model as a Table 2, based on the patterns of distribution of flows of a matter, an energy and an information in the process of mitosis of the cell [14-16]. Note that these data reflect the state of the cell at the moment $t_{0}$. 
Table 2

An example of degenerate dynamic balance model of the cell cycle

\begin{tabular}{|c|c|c|c|c|c|c|c|c|c|c|c|c|c|}
\hline \multicolumn{2}{|c|}{$\begin{array}{l}\text { Intra- } \\
\text { cellular } \\
\text { flows } \\
\end{array}$} & \multicolumn{6}{|c|}{$\begin{array}{l}\text { Intracellular flow, which } \\
\text { is needed to maintain the } \\
\text { functioning of the cell }\end{array}$} & \multicolumn{6}{|c|}{$\begin{array}{l}\text { Increment of intracellular } \\
\text { flows }\end{array}$} \\
\hline & & \multicolumn{2}{|l|}{$\bar{S}$} & \multicolumn{2}{|l|}{$\mathrm{E}$} & \multicolumn{2}{|l|}{ I } & \multicolumn{2}{|l|}{$\bar{S}$} & \multicolumn{2}{|l|}{$\mathrm{E}$} & \multicolumn{2}{|l|}{ I } \\
\hline \multicolumn{2}{|l|}{$\begin{array}{l}j \\
i\end{array}$} & 1 & 2 & 3 & 4 & 5 & 6 & 1 & 2 & 3 & 4 & 5 & 6 \\
\hline \multirow[t]{2}{*}{$\mathrm{S}$} & 1 & 0 & 0,25 & 0 & 0,35 & 0 & 0 & 0 & 0,3 & 0 & 0,2 & 0 & 0 \\
\hline & 2 & 0 & 0 & $\overline{0,2}$ & 0 & 0,05 & 0,05 & 0 & 0 & 0,4 & 0 & 0,1 & 0,1 \\
\hline \multirow[t]{2}{*}{$\mathrm{E}$} & 3 & 0 & 0,3 & 0 & 0,05 & 0,05 & 0 & 0 & 0,4 & 0 & 0,05 & 0,05 & 0 \\
\hline & 4 & $\overline{0,3}$ & 0,1 & $\overline{0,1}$ & 0 & 0,05 & 0,05 & 0,4 & 0 & 0,1 & 0 & 0,05 & 0,05 \\
\hline \multirow[t]{2}{*}{$\mathrm{I}$} & 5 & 0 & 0,1 & $\overline{0,1}$ & 0,1 & 0,1 & 0,1 & 0 & 0,1 & 0,1 & 0,1 & 0,1 & 0,1 \\
\hline & 6 & 0 & 0,1 & $\overline{0,1}$ & 0,1 & 0,2 & 0 & 0 & 0 & 0 & 0 & 0 & 0 \\
\hline \multicolumn{2}{|c|}{ All } & $\overline{0,3}$ & 0,85 & 0,5 & 0,6 & 0,45 & 0,2 & 0,4 & 0,8 & 0,6 & 0,35 & 0,3 & 0,25 \\
\hline
\end{tabular}

System (1) is reduced to a system of Leontieff type

$$
L \dot{x}(t)=M x(t)+y(t)
$$

where $M=I-A, L=B$, and $y(t)=-f(t)$. We construct the matrices of the system (2) using the data of Table 2 .

$$
\begin{gathered}
M=I-A=\left(\begin{array}{cccccc}
1 & -0,25 & 0 & -0,35 & 0 & 0 \\
0 & 1 & -0,2 & 0 & -0,05 & -0,05 \\
0 & -0,3 & 1 & -0,05 & -0,05 & 0 \\
-0,3 & -0,1 & -0,1 & 1 & -0,05 & -0,05 \\
0 & -0,1 & -0,1 & -0,1 & 0,9 & -0,1 \\
0 & -0,1 & -0,1 & -0,1 & -0,2 & 1
\end{array}\right), \\
L=B=\left(\begin{array}{ccccccc}
0 & 0,3 & 0 & 0,2 & 0 & 0 \\
0 & 0 & 0,4 & 0 & 0,1 & 0,1 \\
0 & 0,4 & 0 & 0,05 & 0,05 & 0 \\
0,4 & 0 & 0,1 & 0 & 0,05 & 0,05 \\
0 & 0,1 & 0,1 & 0,1 & 0,1 & 0,1 \\
0 & 0 & 0 & 0 & 0 & 0
\end{array}\right) .
\end{gathered}
$$

Suppose that a contacting of the cell with the external environment during the time interval $\left(t_{0}, \tau\right)$ is determined by vector-function

$$
y(t)=\left(\begin{array}{l}
0,05+10 t+10 t^{2}+10 t^{3} \\
0,9 t+t+5 t^{2}+2 t^{3}+2 t^{4} \\
0,2+65 t+550 t^{2}+400 t^{3}+20 t^{4}+10 t^{5} \\
0,1+755 t+100 t^{2}+800 t^{3}+20 t^{4}+10 t^{5}+t^{6} \\
50 t+200 t^{2}+50 t^{3}+50 t^{4}+t^{5}+t^{6} \\
-t-t^{2}
\end{array}\right) .
$$


This representation of a contacting of the flows of matter, an energy and an information with the external environment during the mitosis corresponds to meeting the needs of the cell by the resources of the external environment and the outflow of the production resources of the cell into the external environment during the time.

\section{Algorithm of the numerical research of the dynamic balance model of the cell cycle}

We use the ideas of the numerical solution of problems for the systems of Leontieff type [17]. The theorem about the existence of a unique solution of Showalter - Sidorov problem

$$
\left[R_{\mu}^{L}(M)\right]^{p+1}\left(x(0)-x_{0}\right)=0
$$

for the system of Leontieff type (2) is presented below without proof.

Theorem 1. [17] Let a matrix $M$ be $(L, p)$-regular, $p \in \mathbb{N}_{0}$ and a matrix $M^{-1}$ exist. Then, for any $x_{0} \in \mathbb{R}^{n}$ and $C \in \mathbb{C}^{p+1}\left((0, \tau) ; \mathbb{R}^{n}\right) \cap \mathbb{C}^{p}\left([0, \tau] ; \mathbb{R}^{n}\right)$ there exists a unique solution of the problem (2), (6) of the form.

$$
\begin{gathered}
x(t)=\lim _{k \rightarrow+\infty} x_{k}(t)= \\
=\lim _{k \rightarrow \infty}\left[-\sum_{q=0}^{p} H^{q} M_{0}^{-1}\left(I-Q_{k}\right) y^{(q)}(t)+X_{k}^{t} x_{0}+\int_{0}^{t} R_{k}^{t-s} Q_{k} y(s) d s\right],
\end{gathered}
$$

where

$$
\begin{gathered}
Q_{k}=\left(k L_{k}^{L}(M)\right)^{p+1}, \quad X_{k}^{t}=\left[\left(L-\frac{t}{k(p+1)} M\right)^{-1} L\right]^{k}, \\
R_{k}^{t}=\left[\left(L-\frac{t}{k(p+1)} M\right)^{-1} L\right]^{k-1}\left(L-\frac{t}{k(p+1)} M\right)^{-1} .
\end{gathered}
$$

Let us begin to construct the algorithm of the numerical solution of Showalter - Sidorov problem for the dynamic balance model of the cell cycle. Note that an order of the square matrix $M$ may be large enough. Therefore if $\operatorname{det} M=0$ (up to $\varepsilon=10^{-30}$ ) it is necessary to make the change $x=e^{\lambda t} v$ and to consider an equation

$$
L \dot{v}=(M-\lambda L) v+e^{-\lambda t} y
$$

where $\operatorname{det}(M-\lambda L) \neq 0$.

The first step of the algorithm is to find $p \in \mathbb{N}_{0}$. Consider the polynomial

$$
\operatorname{det}(\mu L-M)=a_{n} \mu^{n}+a_{n-1} \mu^{n-1}+\ldots+a_{1} \mu+a_{0} .
$$

The coefficients $a_{q}, q=0,1, \ldots, n$ are defined by the formula

$$
a_{q}=(-1)^{n-q} \sum_{r=1}^{C_{n}^{n-q}} \Delta_{n-q}^{r}, q=0,1, \ldots, n
$$


where $\Delta_{n-q}^{r}$ are the determinants which are obtained from determinant of a matrix $L$ by replacing $n-q$ columns by corresponding columns of matrix $M$, and $r$ is the serial number of the determinant.

So, for $n=3$ we obtain

$$
\begin{gathered}
a_{3}=\operatorname{det} L=\operatorname{det}\left(\begin{array}{ccc}
l_{11} & l_{12} & l_{13} \\
l_{21} & l_{22} & l_{23} \\
l_{31} & l_{32} & l_{33}
\end{array}\right), \\
a_{2}=-\operatorname{det}\left(\begin{array}{ccc}
m_{11} & l_{12} & l_{13} \\
m_{21} & l_{22} & l_{23} \\
m_{31} & l_{32} & l_{33}
\end{array}\right)-\operatorname{det}\left(\begin{array}{ccc}
l_{11} & m_{12} & l_{13} \\
l_{21} & m_{22} & l_{23} \\
l_{31} & m_{32} & l_{33}
\end{array}\right)-\operatorname{det}\left(\begin{array}{ccc}
l_{11} & l_{12} & m_{13} \\
l_{21} & l_{22} & m_{23} \\
l_{31} & l_{32} & m_{33}
\end{array}\right), \\
a_{1}=\operatorname{det}\left(\begin{array}{ccc}
m_{11} & m_{12} & l_{13} \\
m_{21} & m_{22} & l_{23} \\
m_{31} & m_{32} & l_{33}
\end{array}\right)+\operatorname{det}\left(\begin{array}{ccc}
m_{11} & l_{12} & m_{13} \\
m_{21} & l_{22} & m_{23} \\
m_{31} & l_{32} & m_{33}
\end{array}\right)+\operatorname{det}\left(\begin{array}{ccc}
l_{11} & m_{12} & m_{13} \\
l_{21} & m_{22} & m_{23} \\
l_{31} & m_{32} & m_{33}
\end{array}\right), \\
a_{0}=-\operatorname{det} M=-\operatorname{det}\left(\begin{array}{ccc}
m_{11} & m_{12} & m_{13} \\
m_{21} & m_{22} & m_{23} \\
m_{31} & m_{32} & m_{33}
\end{array}\right) .
\end{gathered}
$$

After that we determine a number of the older non-zero coefficient $a_{q}$ and denote this number by $q$. Therefore $q=\operatorname{deg} \operatorname{det}(\mu L-M)$. As a result, $p=n-q$.

The second step of the algorithm is to determine a number $K$ such that we can begin to calculate the approximate solution from $K$. Consider the polynomial

$$
\operatorname{det}(\mu L-M)=a_{q} \mu^{q}+a_{q-1} \mu^{q-1}+\ldots+a_{1} \mu+a_{0},
$$

we find

$$
\alpha=\max \left\{1,\left|a_{q}\right|^{-1} \sum_{i=0}^{q}\left|a_{i}\right|\right\}
$$

and then

$$
k_{1}=\frac{1}{\alpha} \sum_{i=0}^{q}\left|a_{i}\right|+1
$$

Consider the polynomial

$$
\begin{aligned}
\operatorname{det}(\mu(p+1) L-t M)= & a_{q} t^{n-q} \mu^{q}(p+1)^{q}+a_{q-1} t^{n-q+1} \mu^{q-1}(p+1)^{q-1}+\ldots+ \\
& +a_{1} t^{n-1} \mu(p+1)+t^{n} a_{0},
\end{aligned}
$$

where $a_{q} \neq 0, q \leq \operatorname{rank} L$. Then for $|t|<1$

$$
k_{2}=\frac{1}{\alpha p^{p}} \sum_{i=0}^{q}\left|a_{i}\right|(p+1)^{n-i}+1,
$$

and $K=\max \left\{k_{1}, k_{2}\right\}$. As a result, for $k \geq K$ we can not even be near the $L$-spectrum of operator $M$. 
The third step of the algorithm is to calculate nodes $s_{j}$ and weights $\omega_{j}$ for a given $\eta$ and an interval of integration $[0 ; \tau]$.

$$
\int_{0}^{\tau} f(x) d x \approx \frac{\tau}{2} \sum_{i=1}^{2 \eta-1} \omega_{j} f\left(\frac{\tau}{2}+\frac{\tau}{2} s_{j}\right), j=\overline{1,2 \eta-1}
$$

where $s_{j}$ are the zeros of Legendre polynomial

$$
P_{n}(t)=\frac{1}{2^{n} n !} \cdot \frac{d^{n}}{d t^{n}}\left[\left(t^{2}-1\right)^{n}\right], n=0,1
$$

and weights are determined by the formula

$$
\omega_{j}=\frac{2}{\left[P_{n}^{\prime}\left(s_{j}\right)\right]^{2}\left(1-s_{j}\right)^{2}} .
$$

Next step of the algorithm is to determine a time $\tau$, at which the doubling of resources is achieved.

The last step of the algorithm is to calculate $x_{k}(t)$ for a given $t \in\left[t_{0}, \tau\right]$. We do it componentwise using the formula (7).

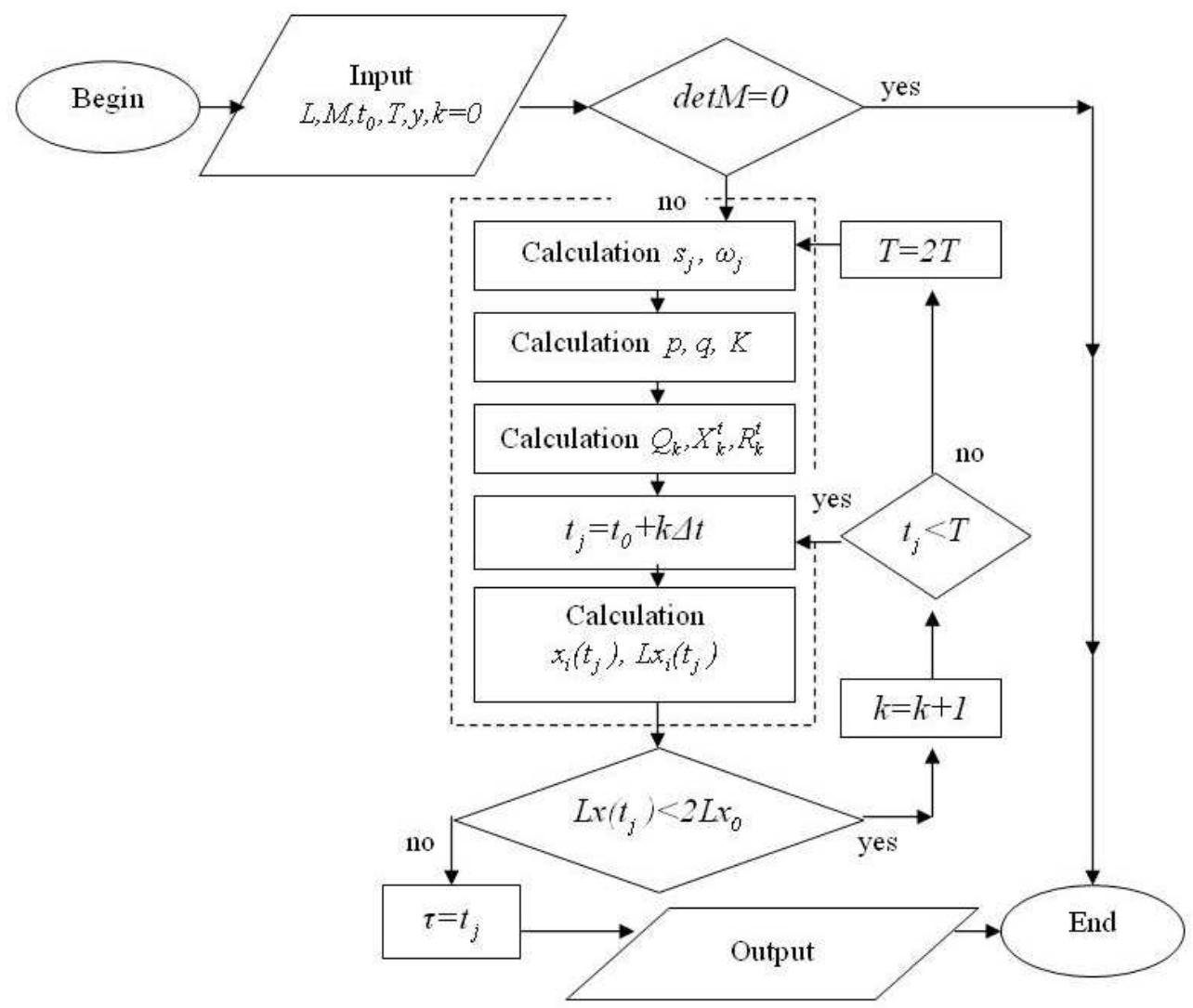

Fig. 1. Block diagram of the algorithm of the numerical solution of the cell cycle model 


\section{Results of a computational experiment}

Consider the numerical research of the model example of a degenerate balance dynamic model of the cell cycle for the matrices (3), (4), where the interaction of the cell with the external environment is defined by a vector - function (5).

In Fig. 2 a cell actively grows in size, stores the matter which are necessary for a division: proteins, nucleic acids, lipids. Two types of the flows of matter are considered: 1 type - lipids, proteins, nucleic acids and fats, which are involved in the cleavage; 2 type lipids, proteins, nucleic acids and fats, which are obtained by synthesis. The flow of matter of the first type is bigger, because a cell accumulate matter for a further division.

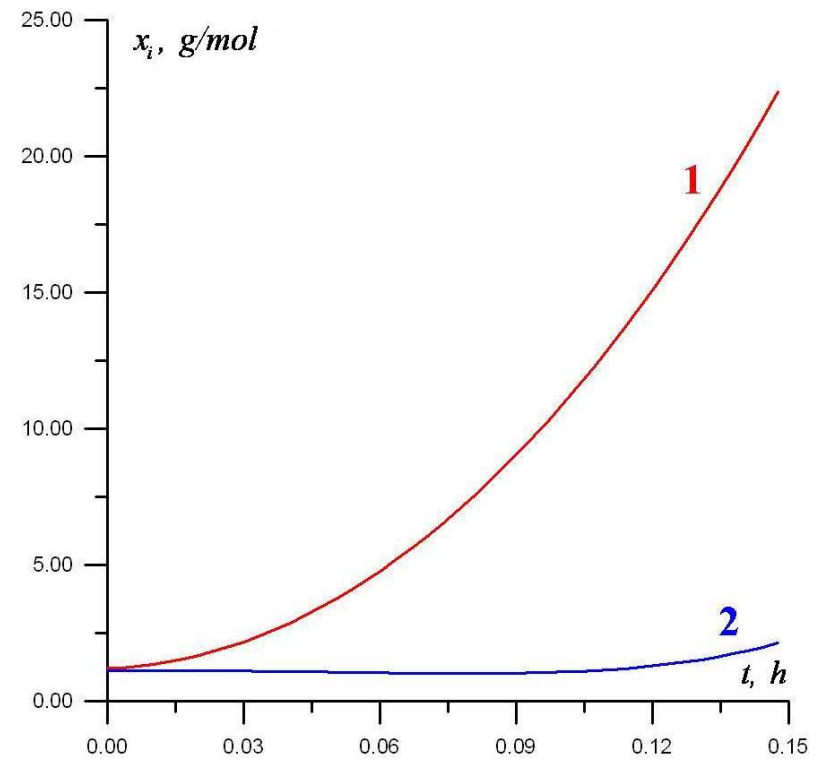

Fig. 2. Matter flows of two types

A certain amount of an energy is required to prepare the cell to divide and to maintain its functioning. This energy is reserved by a cleavage of high-molecular organic compounds (energy of 2 type). Also an energy is absorbed in the synthesis of of matter (energy of 1 type), see Fig. 3. A fission and fusion energy increases with a growth and a following division of the cell. The energy of type 2 is bigger, because an energy is used not only for the synthesis of matter, but also for other processes, e.g., for a transport of matter.

During a cell division the flows of two types are necessary. They provide the transfer of genetic information (type 2) and the regulation of all kinds of cellular activity (type 1) (Fig. 4). DNA accumulates, therefore the flow of genetic information (type 2) continues to grow. During a preparation for a cell division the synthesis of RNA and proteins increases. By the beginning of the process of cell division the flow of information about a regulation of all kinds of cellular activity (type 1) is decreases.

In Fig. 5 the reserve of matter of type 1 (lipids, proteins, nucleic acids, fats, which are involved in a cleavage) is bigger. They are redistributed and are the basis of a new cell. Also a reserve of matter of type 2 (lipids, proteins, nucleic acids, fats, obtained by synthesis) doubles.

Fig. 6 shows the predominance of energy which is reserved by the cleavage of highmolecular organic compounds (energy of type 2). This is due to the fact that the formation 


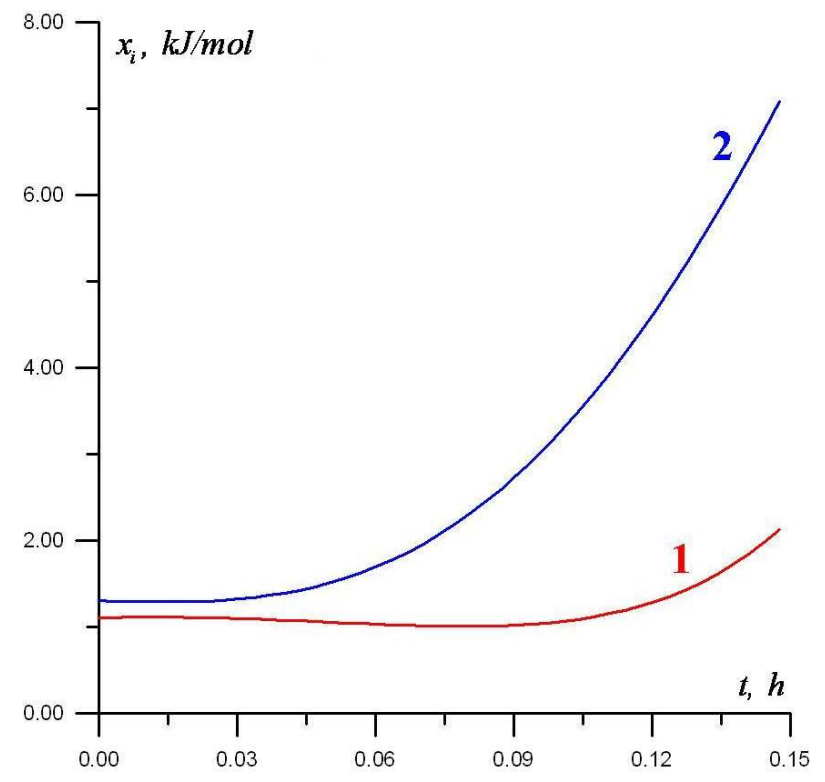

Fig. 3. Energy flows of two types



Fig. 4. Information flows of two types

of new structures requires substantial energy consumption. The energy reserve of synthesis of matter (energy of type 1) is more prolonged in time.

DNA is not synthesized and an information of type 2 is not accumulated during mitosis (Fig. 7). The nucleus and all its structures are formed on the basis of the synthesized material. It requires a considerable reserve of the flow of an information, which is responsible for the regulation of all kinds of cellular activity (type 1).

The numerical research of a model example provides an opportunity to establish the relationship between the intracellular flows of matter, energy and information and also to understand how the cell functions during mitosis and how the cell interacts with the 


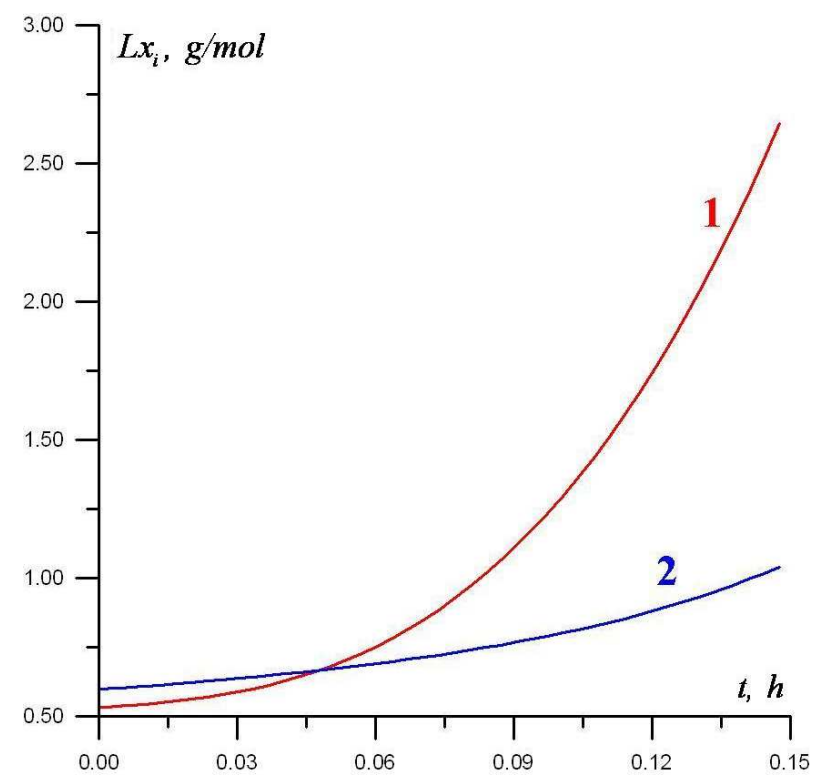

Fig. 5. Reserve matter of two types

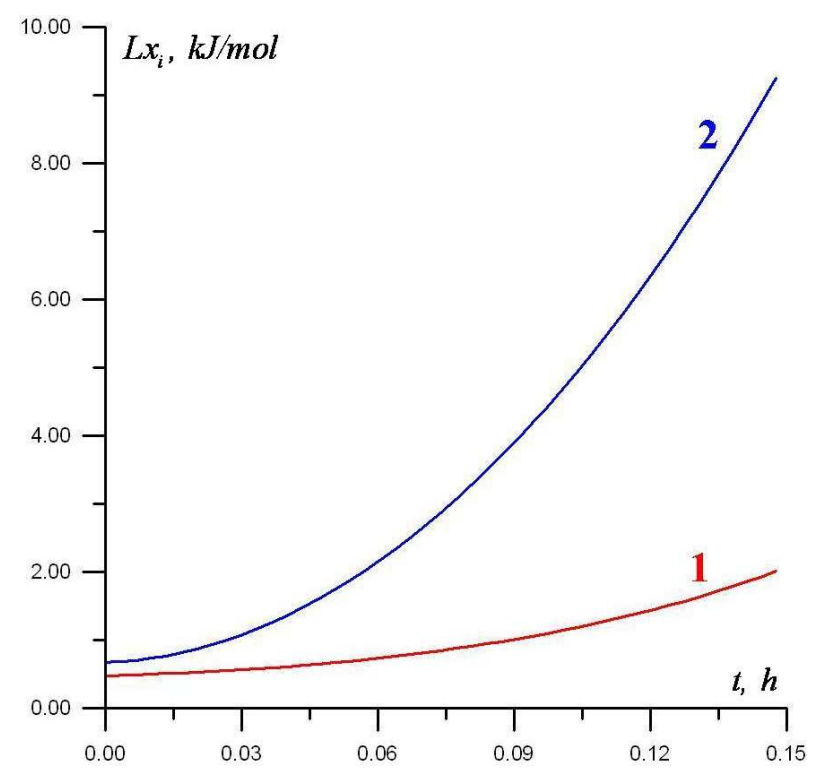

Fig. 6. Reserve information of two types

environment.

\section{References}

1. Sviridyuk G.A., Zagrebina S.A. The Showalter - Sidorov Problem as Phenomena of the Sobolev-Type Equations. The Bulletin of Irkutsk State University. Series "Mathematics", 2010, vol. 3, no. 1, pp. 104-125. (in Russian)

2. Zagrebina S.A. On the Showalter -Џ Sidorov problem. Izv. Vyssh. Uchebn. Zaved. Mat., 2007, no. 3, pp. 22-28. (in Russian) 


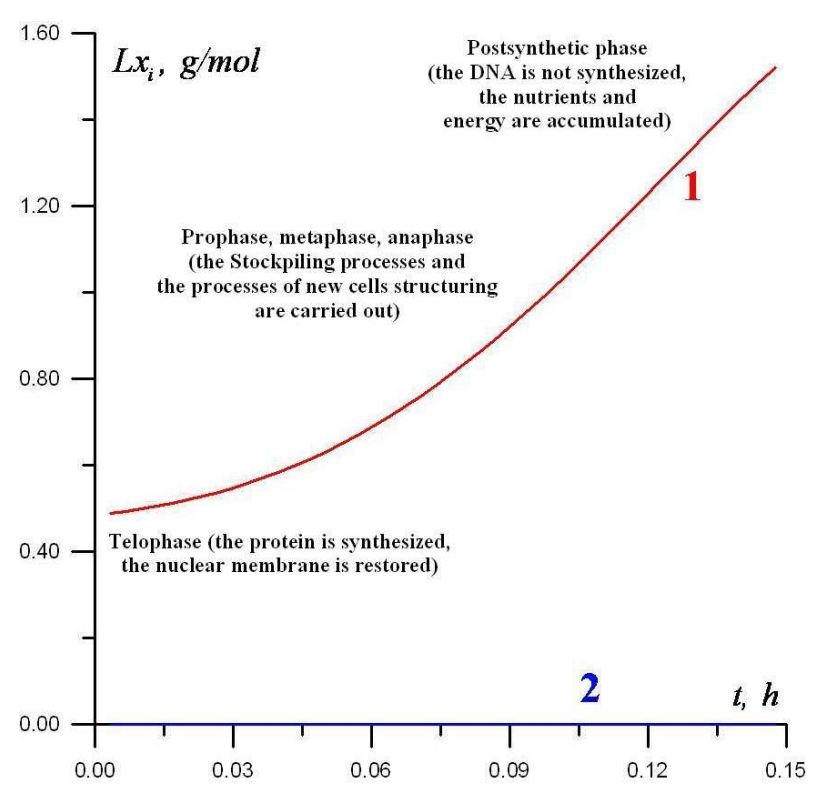

Fig. 7. Reserve information of two types

3. Zamyshlyaeva A.A. The Higher-Order Sobolev Type Models. Bulletin of the South Ural State University. Series "Mathematical Modelling, Programming 8 Computer Software", 2014, vol. 7, no. 2, pp. 5-28. doi: 10.14529/mmp140201 (in Russian)

4. Sagadeeva M.A. A Existance and a Stability of Solutions for Semilinear Sobolev Type Equations in Relatively Radial Case. The Bulletin of Irkutsk State University. Series "Mathematics", 2013, vol. 6, no. 1, pp. 78-88. (in Russian)

5. Manakova N.A., Bogonos E.A. Optimal Control to Solutions of the Showalter - Sidorov Problem for a Sobolev Type Equation. The Bulletin of Irkutsk State University. Series "Mathematics", 2010, vol. 3, no. 1, pp. 42-53. (in Russian)

6. Sviridyuk G.A., Brychev S.V. Numerical Solution of Systems of Equations of Leontieff Type. Izv. Vyssh. Uchebn. Zaved. Mat., 2003, no. 8, pp. 46-52. (in Russian)

7. Burlachko I.V., Sviridyuk G.A. On the Numerical Solution of the Cauchy Problem for a Degenerate Linear System of Ordinary Differential Equations. Tambov University Reports. Series: Natural and Technical Sciences, 2003, vol. 8, no. 3, p. 353. (in Russian)

8. Keller A.V., Shishkina T.A. The Method of Constructing Dynamic and Static Balance Models at the Enterprise Level. Bulletin of the South Ural State University. Series "Economics and Management", 2013, vol. 7, no. 3, pp. 6-10. (in Russian)

9. Shestakov A.L., Sviridyuk G.A. A New Approach to the Measurement of Dynamically Perturbed Signals. Bulletin of the South Ural State University. Series "Mathematical Modeling and Programming \& Computer Software", 2010, no. 16(192), pp. 116-120. (in Russian)

10. Keller A.V., Nazarova E.I. The Regularization Property and the Computational Solution of the Dynamic Measure Problem. Bulletin of the South Ural State University. 
Series "Mathematical Modeling and Programming \& Computer Software", 2010, no. 16(192), pp. 32-38. (in Russian)

11. Shestakov A.L., Sviridyuk G.A., Khudyakov Y.V. Dinamic Measurement in Spaces of "Noise". Bulletin of the South Ural State University. Series "Computer Technologies, Automatic Control $\&$ Radioelectronics", 2013, vol. 13, no. 2, pp. 4-11. (in Russian)

12. Gernet N.D. Carrying a Dynamic Model of the Cell Cycle. Eastern-European Journal of Enterprise Technologies, 2013, vol. 6, no. 4(66), pp. 42-47. (in Russian)

13. Leontieff V.V. [Interindustry Economics]. Moscow, Ekonomika Publ., 1997. (in Russian)

14. Vysotskaya L.V. Mitotic Cycle and its Regulation. The Vavilov Journal of Genetics and Breeding, 2014, vol. 18, no. 1, pp. 81-92. (in Russian)

15. Antonova E.I., Berkova D.I., Sagalbaeva L.E., Shpak O.J. The Dynamics of Cellular Cycle Indices of Ecto- and Endothermic Animals. Journal of New Medical Technologies, 2011, vol. 18, no. 2, pp. 18-20. (in Russian)

16. Keller A.V., Ebel S.I. [About Degenerate Discrete Dynamic Model of the Balance of the Cell Cycle]. Yuzhno-Uralskaya Molodezhnaya Shkola po Matematicheskomu Modelirovaniyu, Chelyabinsk, 29-30 Maya 2014. [South Ural Youth School on Mathematical Modeling, Chelyabinsk, 29-30 May 2014]. Chelyabinsk, Publishing center of SUSU, 2014, pp. 74-79. (in Russian)

17. Keller A.V. The Algorithm for Solution of the Showalter - Sidorov Problem for Leontieff Type Models. Bulletin of the South Ural State University. Series "Mathematical Modeling and Programming $\&$ Computer Software", 2011, no. 4(221), pp. 40-46. (in Russian)

Svetlana I. Ebel, Master of Mathematics, Department of Equation of Mathematical Physics, South Ural State University, Chelyabinsk, Russian Federation, ebelsi@susu.ac.ru.

Received May 17, 2015 